\title{
AN OVERVIEW ON “MEMORY DYSFUNCTION, TYPES OF MEMORY, AND ITS CLINICAL DISORDERS"
}

\author{
ROHIT JAYSING BHOR* \\ Department of Pharmaceutical Chemistry, PRES's College of Pharmacy Chincholi, Sinner, Nasik - 422 103, Maharashtra, India. \\ Email: rohit.bhor69@gmail.com
}

Received: 19 July 2016, Revised and Accepted: 29 August 2016

\section{ABSTRACT}

All things considered, memory debilitation is ordinarily seen by doctors in different controls including neurology, psychiatry, pharmaceutical, and surgery. Memory misfortune is frequently the most crippling element of numerous disarranges, hindering the typical every day exercises of the patients, and significantly influencing their families. A few recognitions about memory, for example, the ideas of "short term" and "long haul" have offered route to a more refined understanding and enhanced order frameworks. These progressions result from neuropsychological investigations of patients with central mind injuries, neuroanatomical studies in people and creatures, tests in creatures, positron-discharge tomography, useful attractive reverberation imaging, and possibilities. Memory is presently comprehended to be a gathering of mental capacities that rely on a few frameworks inside the cerebrum. In this article, we will talk about the accompanying four memory frameworks that are of clinical significance: Wordy memory, semantic memory, procedural memory, and working memory. Memory frameworks can be isolated into those that are definitive and those that are non-decisive. Revelatory or express memory will be memory for occasions that can be deliberately reviewed. Non-definitive or verifiable memory, by correlation, is memory that is communicated as an adjustment in conduct and is regularly oblivious.

Keywords: Episodic memory, Semantic memory, Working memory, Agnosia, Brain injury, Alzheimer's disease, Huntington's disease, WernickeKorsakoff's Syndrome.

(C) 2016 The Authors. Published by Innovare Academic Sciences Pvt Ltd. This is an open access article under the CC BY license (http://creativecommons. org/licenses/by/4. 0/) DOI: http://dx.doi.org/10.22159/ajpcr.2016.v9s3.14195

\section{INTRODUCTION}

Memory capacity is pathologic procedures including neurodegenerative illnesses, strokes, tumors, head injury, hypoxia, heart surgery, lack of healthy sustenance, a lack of ability to concentrate consistently clutter, misery, uneasiness, the symptoms of solution, and typical maturing [1]. Thusly, memory disability is regularly seen by doctors in numerous orders including neurology, psychiatry, medication, and surgery. Memory misfortune is frequently the most debilitating component of numerous scatters, impeding the ordinary everyday exercises of the patients, and significantly influencing their families [2,3]. A few discernments about memory, for example, the ideas of "short term" and "long haul" have offered path to a more refined understanding and enhanced grouping frameworks. These progressions result from neuropsychological investigations of patients with central cerebrum sores, neuroanatomical studies in people and creatures, tests in creatures, positron-emanation tomography, practical attractive reverberation imaging, and occasion-related possibilities $[4,5]$. Memory is currently comprehended to be a gathering of mental capacities that rely on a few frameworks inside the cerebrum. In this article, we will examine the accompanying four memory frameworks that are of clinical pertinence: Roundabout memory, semantic memory, procedural memory, and working memory [6,7]. We will condense the present comprehension of memory from the perspective of practical neuroimaging and investigations of patients with cerebrum affronts, which ought to help clinicians in the determination and treatment of the memory issue of their patients [8]. As helpful mediations for memory issue get to be accessible, clinicians will progressively know about the different memory frameworks in the cerebrum $[9,10]$. A memory framework is a route for the cerebrum to process data that will be accessible for use at a later time. Diverse memory frameworks rely on various neuroanatomical structures. A few frameworks are connected with cognizant mindfulness (unequivocal) and can be deliberately reviewed (definitive), though others are communicated by an adjustment in conduct (understood) and are regularly oblivious (non-revelatory) [11]. Memory can likewise be classified in numerous different routes, for example, by way of the material to be recollected.
The objective of this article is to give an outline of the six essential memory frameworks, their pertinent neuro life structures and the clinical issue that upset them. By "memory framework," we mean a path, in which the cerebrum forms data that is accessible for use at a later time, with or without cognizant mindfulness [12-14]. These memory frameworks can, from a certain point of view, be separated from each other. As we will see, a few infection states principally influence one memory framework, and numerous others influence different frameworks [15]. Memory frameworks can be partitioned into those that are definitive and those that are non-explanatory. Revelatory or express memory will be memory for occasions that can be intentionally reviewed. Non-decisive or certain memory, by correlation, is memory that is communicated as an adjustment in conduct and is frequently oblivious [16].

\section{Short introduction of memory disorders [17-20] \\ Agnosia}

Agnosia is the powerlessness to perceive certain articles, persons, or sounds. Agnosia is regularly brought about by harm to the cerebrum, i.e., most generally in the occipital or parietal flaps or from a neurological issue. Agnosia medicines differ contingent on the area and reason for the harm. Recuperation is conceivable relying on the seriousness of the confusion and the seriousness of the harm to the cerebrum. There are a few cases agnosia such as associative visual agnosia, astereognosis, auditory agnosia, auditory verbal agnosia, and land bewilderment and visual agnosia.

\section{Alzheimer's disease (AD)}

Alzheimer's ailment (AD) is a dynamic, degenerative, and deadly cerebrum ailment, in which cell-to-cell associations in the mind are lost. Alzheimer's illness is the most well-known type of dementia. All inclusive roughly $1-5 \%$ of the populace is influenced by Alzheimer's sickness. Ladies are lopsidedly the casualties of Alzheimer's malady, with confirmation recommending that ladies with AD show more serious psychological debilitation in respect to age-coordinated guys with $\mathrm{AD}$, and in addition a more fast rate of subjective decrease. 


\section{Amnesia}

Amnesia is a strange mental state, in which memory and learning are influenced out of all extent to other psychological capacities in a generally ready and responsive patient. There are two sorts of amnesia: Anterograde amnesia and retrograde amnesia (RA). Anterograde amnesia shows trouble in the learning and maintenance of data experienced after mind harm.

\section{Brain injury}

Traumatic mind harm regularly happens from harm to the cerebrum brought on by an outside power and may prompt instances of amnesia relying on the seriousness of the damage. Head damage can offer ascent to either transient or holding on amnesia. Once in a while, posttraumatic amnesia may exist with no RA, yet this is frequently more regular in instances of entering sores. Harm to the frontal or foremost fleeting areas has been depicted to be connected with unbalanced RA. As noted in the aforementioned area on traumatic mind harm it can be connected with memory weakness, Alzheimer's illness; be that as it may, similarly as maturing is concerned it postures different dangers also. There is confirmation that backings a high rate of falls among the elderly populace and this is the main source of traumatic brain injury (TBI)-related passing among the number of inhabitants in individuals 75 years old and more established. At the point when taking a gander at the outline to one side on the page, it expresses that falls are just $28 \%$ of the aggregate reasons for TBI so that would recommend that the elderly make up a decent partition of that $28 \%$ general. Cerebrum wounds can likewise be the aftereffect of a stroke as the subsequent absence of oxygen can make harm the area of the cerebrovascular mischance (CVA). The impacts of a CVA in the left and right halves of the globe of the cerebrum incorporate transient memory disability, and trouble procuring and holding new data.

\section{Dementia}

Dementia alludes to a huge class of scatters described by the dynamic weakening of deduction capacity and memory as the mind gets to be harmed. Dementia can be classified as reversible (e.g., thyroid infection) or irreversible (e.g., Alzheimer ailment). As of now, there are more than 35 million individuals with dementia around the world. In the United States, alone the quantity of individuals influenced by dementia is striking at 3.8 million.

\section{Huntington's disease (HD)}

HD is an acquired dynamic issue of the mind that prompts uncontrolled developments, enthusiastic flimsiness, and loss of scholarly faculties. Because of the inheritability of Huntington's every youngster destined to a guardian with Huntington's has a half risk of acquiring the illness, prompting a pervasiveness of right around 1 in 10,000 Canadians $(0.01 \%)$.

\section{Parkinson's disease}

Parkinson's illness (PD) is a neurodegenerative ailment. Development is ordinarily controlled by Dopamine; a compound that conveys signals between the nerves in the mind. At the point when cells that typically create dopamine vanish, the indications of Parkinson's show up. The most widely recognized side effects include: Tremors, gradualness, solidness, weakened equalization, unbending nature of the muscles, and exhaustion. As the illness advances, non-engine indications may likewise show up, for example, despondency, trouble gulping, sexual issues, or subjective changes.

\section{Wernicke-Korsakoff's Syndrome (WKS)}

Wernicke-Korsakoff's Syndrome is otherwise called WKS. WKS is a serious neurological issue brought about by thiamine (vitamin B1) inadequacy and is generally connected with unending extreme liquor utilization. WKS is described clinically by oculomotor variations from the norm, cerebellar brokenness, and a modified mental state. Korsakoff's disorder is additionally portrayed by significant amnesia, bewilderment and making up or designing data to adjust for poor memory.

\section{TYPES OF MEMORY AND ITS CLINICAL DISORDERS [21-25]}

Memory can be divided into four groups such as episodic memory, semantic memory, procedural memory, and working memory (Table 1).

\section{Episodic memory}

Roundabout memory is used to the express and revelatory memory framework used to review individual encounters encircled in our own particular connection, for example, a short story or what you had for supper the previous evening [26]. Wordy memory has to a great extent been characterized by powerlessness of individuals with amnesia because of injuries of the average transient projection to recollect encounters that sound individuals can recall. In this way, this memory framework relies on the average worldly projections. Memory misfortune inferable from brokenness of the rambling memory framework takes after an anticipated example known as Ribot's law, which expresses that occasions just before an ictus are most helpless against disintegration, though remote recollections are generally safe. Along these lines, in instances of brokenness of the wordy memory framework, the capacity to learn new data is impeded (anterograde amnesia), as of late learned data cannot be recovered (RA), and remotely learned data are typically saved [27]. Thinks about have demonstrated that the verbose memory framework incorporates the frontal projections. Instead of being in charge of the maintenance of data, the frontal projections are included in the enrollment, securing, or encoding of data; the recovery of data without relevant and different signs; the memory of the wellspring of data; and the appraisal of the transient grouping and regime of occasions. Amazing case of memory

Table 1: Types of memory

\begin{tabular}{|c|c|c|c|c|c|}
\hline S. No. & Memory system & $\begin{array}{l}\text { Major anatomical structures } \\
\text { involved }\end{array}$ & $\begin{array}{l}\text { Length of } \\
\text { storage of } \\
\text { memory }\end{array}$ & $\begin{array}{l}\text { Type of } \\
\text { awareness }\end{array}$ & Examples \\
\hline 1 & Episodic memory & $\begin{array}{l}\text { Medial temporal lobes, anterior } \\
\text { thalamic nucleus, mammillary } \\
\text { body, fornix, prefrontal cortex }\end{array}$ & $\begin{array}{l}\text { Minutes } \\
\text { to year }\end{array}$ & $\begin{array}{l}\text { Explicit, } \\
\text { declarative }\end{array}$ & $\begin{array}{l}\text { Remembering a short story, what you } \\
\text { had for dinner last night, and what you } \\
\text { did on your last birthday }\end{array}$ \\
\hline 2 & Semantic memory & Infer lateral temporal lobes & $\begin{array}{l}\text { Minutes } \\
\text { to year }\end{array}$ & $\begin{array}{l}\text { Explicit, } \\
\text { declarative }\end{array}$ & $\begin{array}{l}\text { Knowing who was the first president } \\
\text { of the United States, the color of a lion, } \\
\text { and how a fork differs from a comb }\end{array}$ \\
\hline 3 & Procedural memory & $\begin{array}{l}\text { Basal ganglia, cerebellum, } \\
\text { supplementary motor area }\end{array}$ & $\begin{array}{l}\text { Minutes } \\
\text { to year }\end{array}$ & $\begin{array}{l}\text { Explicit or } \\
\text { implicit, } \\
\text { non-declarative }\end{array}$ & $\begin{array}{l}\text { Driving a car with a standard } \\
\text { transmission (explicit) and learning the } \\
\text { sequence of numbers on a touch-tone } \\
\text { phone without trying (implicit) }\end{array}$ \\
\hline 4 & Working memory & $\begin{array}{l}\text { Phonologic: Prefrontal cortex, } \\
\text { Broca's area, Wernicke's area } \\
\text { Spatial: Prefrontal cortex, } \\
\text { visual-association areas }\end{array}$ & $\begin{array}{l}\text { Seconds } \\
\text { to } \\
\text { minutes }\end{array}$ & $\begin{array}{l}\text { Explicit, } \\
\text { declarative }\end{array}$ & $\begin{array}{l}\text { Phonologic: Keeping a phone number } \\
\text { "in your head" before dialing } \\
\text { Spatial: Mentally following a route or } \\
\text { rotating an object in your mind }\end{array}$ \\
\hline
\end{tabular}


twists incorporate confabulation, which happens when "recollections" are made to be predictable with current data, for example, "recalling" that somebody broke into the house and reworked family unit things [28]. These contrasts between shortages in roundabout memory that happen as a result of harm to the average worldly projections and those that happen in view of harm to the frontal flaps can be conceptualized in a distorted yet clinically helpful similarity. Different disarranges of memory, for example, those because of prescriptions, hypoglycemia, tumors, and Korsakoff's disorder, can have a more convoluted and variable time course [29]. Once turmoil of roundabout memory is associated on the premise with a reported powerlessness to recollect late data and encounters precisely, extra assessment is justified. Research facility and imaging studies will more often than not be demonstrated, by differential determination. Treatment relies on the particular issue. Cholinesterase inhibitors and Memantine have been endorsed by the Food and Drug Administration to treat Alzheimer's illness; the previous have additionally been utilized to treat vascular dementia and dementia with Lewy bodies. Two late audits talk about the adequacy of these medicines [30].

\section{Clinical disorders of episodic memory \\ $A D$}

Alzheimer infection (AD) is the most well-known neurodegenerative malady in adulthood and the most well-known illness that influences the long winded memory framework. The hippocampus and other average fleeting projection structures are harmed by AD initially, and to a more noteworthy degree than other mind ranges. Patients with $\mathrm{AD}$ build up an amnesic issue, abandoning them debilitated or not able to learn new data. Hence, they start to lose as of late procured information. As examined underneath, they experience the ill effects of twists of memory that can disable their capacity to live freely notwithstanding their inability to learn and recover data; for instance, patients may trust that they killed the stove when they have just pondered turning it off. At last, as the pathology of $\mathrm{AD}$ starts to influence more far reaching regions of the mind, these patients create issues with other intellectual capacities and cannot perform exercises of day by day living, for example, eating, dressing, and showering.

\section{Korsakoff's syndrome}

Korsakoff's disorder ordinarily happens when a constant alcoholic patient experiences poor sustenance and specifically creates thiamine inadequacy. There is lost neurons and myelinated nerve filaments in a few cerebrum structures. Other intellectual capacities are moderately protected. In spite of the fact that Korsakoff's disorder is unprecedented, the psychological profile of these patients has been concentrated widely in view of the chance to inspect patients with generally particular intellectual and neurotic shortfalls. Other than the failure to learn new data, patients with Korsakoff's disorder likewise experience the ill effects of memory mutilations and out and out confabulations. As is examined underneath, these bended recollections are to a limited extent because of frontal projection brokenness auxiliary to harm of the dorsomedial thalamic cores that have vigorous associations with the frontal flaps.

\section{Transient global amnesia (TGA)}

TGA is an extraordinary issue that is striking both for its specific neuropsychological brokenness and for its brief and kindhearted nature. Despite the fact that its etiology is obscure, there have all the earmarks of being an epidemiological relationship among TGA and headache. Vascular occasions and seizures are additionally a thought. Precipitants of TGA incorporate mental anxiety, showering and physical effort. Patients intensely build up a particular issue of roundabout memory; losing from a few to $48 \mathrm{~h}$ of beforehand learned data and cannot learn new data. Patients frequently over and over ask, "Where am I?" and "What am I doing here?" Other memory frameworks and intellectual capacities are saved. Conduct is generally ordinary, as are discoveries on neurological examination. There is no obfuscating of awareness or loss of individual personality. Practical imaging concentrates on including positron-discharge tomography, single-photon emanation figured tomography, and dissemination attractive reverberation imaging (magnetic resonance imaging) have shown variations from the norm of Papez circuit.

\section{Other diseases}

Other diseases can affect episodic memory by damaging the Papez circuit. These include: Infections (such as herpes simplex virus that has a predilection for the medial temporal lobes), tumors or other mass lesions (especially of the diencephalon), strokes (particularly of the thalamus), hypo ischemic injury such as follows cardiac arrest, head trauma (frontal and temporal lobes are often injured), and iatrogenic causes (e.g., removal of the medial temporal lobe).

\section{Ribot's law}

Memory loss in episodic memory and thus in the clinical disorders described above follows a particular pattern that has come to be known as Ribot's law: Ability to learn new information is most impaired (anterograde amnesia), recently learned information cannot be retrieved (RA), and remotely learned information is spared.

\section{Semantic memory}

Semantic memory eludes to our general store of theoretical and real information, for example, the shade of a lion or the primary president of the United States that is not identified with a particular memory. Like rambling memory, semantic memory is a revelatory and unequivocal memory framework. There is proof, for instance, that visual pictures are put away in close-by visual-affiliation ranges. Nonetheless, a more prohibitive perspective of semantic memory, one that is defended in light of the naming and order errands by which it is normally measured, limits semantic memory to the construe sidelong fleeting flaps. In Alzheimer's illness, wordy, and semantic memory decay autonomously of each other, supporting two separate memory frameworks are weakened in this issue. Clutters of semantic memory ought to be suspected when patients experience issues naming things whose names they beforehand knew. The assessment for disarranges of semantic memory ought to incorporate the same segments as the assessment utilized for clutters of wordy memory [31]. The history and psychological examination ought to discover whether the issue is exclusively owing to a trouble in reviewing individuals' names and other formal people, places, or things, which is basic, especially in solid more established grown-ups, or to a genuine loss of semantic data. Patients with gentle brokenness of semantic memory may indicate just lessened era of words for semantic classifications (e.g., the quantity of names of creatures that can be produced in one moment), though patients with a more serious disability of semantic memory commonly demonstrate a two-way naming shortfall.

\section{Clinical disorders of semantic memory $A D$}

The most widely recognized clinical issue that shows semantic memory deficiencies is AD. Notwithstanding having pathology in average fleeting and prefrontal cortex, patients with $\mathrm{AD}$ demonstrate pathology in horizontal worldly flaps. This is one motivation behind why patients with $\mathrm{AD}$ experience issues concocting names not just of individuals (which is regular in more established grown-ups) additionally of different sorts of items. Despite the fact that we might be enticed to attempt to interface the semantic memory shortage in $\mathrm{AD}$ to the wordy memory brokenness [32], Greene and Hodges (1996) have demonstrated that these two memory frameworks decrease autonomously in AD. It is the demolition of the semantic memory framework that causes patients with $\mathrm{AD}$ at last to lose all information about the world, even their own particular name and capacity to remember them in a mirror.

\section{Other diseases}

\section{Autobiographical memory}

There stay a few intriguing and uncertain issues with respect to personal memory and its relationship to semantic memory. Case reports have been 
distributed of a few patients who displayed moderately particular loss of their remote self-portraying memory in the wake of agony reciprocal harm to the front segment of their horizontal transient projections. These patients, similar to those with semantic dementia, display an opposite Ribot design: They can recollect as of late learned data over minutes, days, or weeks, yet cannot review their remote past, for example, adolescence and school recollections, or recollections of their folks, life partner, kids, and so forth. These patients quite often have confirmation of harm to different parts of the semantic memory framework. The legitimacy of the self-portraying memory writing has been addressed, in any case, since a few patients present with a personal amnesic disorder that does not seem, by all accounts, to be physiologically conceivable. For instance, regularly taking after minor head harm, a patient will not have the capacity to recollect his or her name or other self-portraying data, despite the fact that the wordy and semantic memory frameworks give off an impression of being generally in place [33].

\section{Working memory}

Working memory is a blend of the conventional fields of consideration, fixation, and transient memory. It alludes to the capacity to briefly keep up and control data that one needs to remember. Since it requires dynamic and cognizant cooperation, working memory is an unequivocal and decisive memory framework. Working memory has customarily been isolated into segments that procedure phonologic data (e.g., keeping a telephone number "in your mind") or spatial data (e.g., rationally taking after a course) and an official framework that allots consideration assets [34]. Various studies have demonstrated that working memory utilizes a system of cortical and sub-cortical territories, contingent on the specific errand. Nonetheless, essentially all undertakings including working memory require cooperation of the prefrontal cortex. Commonly, the system of cortical and subcortical regions incorporates back cerebrum districts (e.g., visual-affiliation regions) that are connected with prefrontal locales to frame a circuit. Concentrates on have demonstrated that phonologic working memory has a tendency to include more locales on the left half of the cerebrum, though spatial working memory has a tendency to include more districts on the right side. Concentrates on have demonstrated that patients with Alzheimer's, Parkinson's, or Huntington's malady or dementia with Lewy bodies, and in addition less normal issue, for example, dynamic supra-atomic paralysis, may indicate hindered working memory. Such procedures incorporate strokes, tumors, head damage, and various scleroses among others. Since phonologic working memory includes the noiseless practice of verbal data, any sort of aphasia can likewise impede it. In spite of the fact that the pathophysiology is not surely knew, disarranges that decrease consideration assets, for example, consideration shortfall hyperactivity issue, over the top urgent issue, schizophrenia, and despondency, can likewise hinder working memory. A confusion of working memory can show in a few ways [35]. Most normally, the patient will demonstrate a failure to focus or focus. Trouble playing out another errand including multistep guidelines might be seen. In such cases, the assessment will demonstrate an essential disappointment of encoding, on the grounds that with a specific end goal to move data into wordy memory, the data should first be "remembered" by working memory.

\section{Clinical disorders of working memory}

Since WM is reliant on a system of movement that incorporates sub cortical structures and in addition foremost and back cortical locales, numerous neurodegenerative maladies show impedance in WM undertakings. Contemplates have exhibited that patients with $\mathrm{PD}, \mathrm{HD}, \mathrm{AD}$, and less basic issue, for example, dynamic supra atomic paralysis is weakened on undertakings of spatial WM. Notwithstanding neurodegenerative sicknesses, any infection procedure that disturbs the frontal flaps or their associations with back cortical areas and sub cortical structures can meddle with WM. Such procedures incorporate strokes, tumors, head damage, and different sclerosis among others.

\section{Procedural memory}

Procedural memory is the capacity to learn behavioral and intellectual aptitudes and calculations that work on a programed, oblivious level.
Cases incorporate riding a bicycle or driving a standard transmission car Since procedural memory is saved in patients with serious deficiencies of the roundabout memory framework, for example, those with Korsakoff's disorder, AD, and surgical evacuation of the average worldly projections, we realize that procedural memory speaks to a different and particular memory framework. Procedural memory alludes to the capacity to learn behavioral and psychological aptitudes and calculations that are utilized at a programed, oblivious level. Procedural memory is non-definitive yet amid procurement might be either express, (for example, figuring out how to drive an auto with a standard transmission) or certain, (for example, taking in the arrangement of numbers on a touch-tone telephone without cognizant exertion) [36]. Research with the utilization of useful imaging has demonstrated that cerebrum locales required in procedural memory, including the supplementary engine territory, basal ganglia, and cerebellum, get to be dynamic as another assignment is being educated. Validating confirmation originates from investigations of patients with sores in the basal ganglia or cerebellum who show debilitation in learning procedural aptitudes. Since the malady procedure in early Alzheimer's ailment influences cortical and limbic structures while saving the basal ganglia and cerebellum, these patients show shortfalls in long winded memory, however, typical securing and upkeep of procedural aptitudes. Parkinson's ailment is the most widely recognized issue influencing procedural memory [37]. Other neurodegenerative maladies that disturb procedural memory incorporate Huntington's ailment and olivopontocerebellar degeneration.

\section{Clinical disorders of procedural memory}

Strokes

One illustration is of a young fellow we have nurtured who experienced a stroke in the left putamen. He lost the capacity to perform most programed, talented developments, for example, the demonstration of composing and swinging a golf club. In spite of the fact that he has possessed the capacity to relearn the basics of these abilities, even quite a long while later they keep on requiring express considering: He lost a significant part of the programed ease of straightforward engine errands that the greater part of us underestimate. Challenges in learning procedural abilities are also found in patients with strokes of the cerebellum.

Degenerative and other diseases

Notwithstanding strokes, any reason for basal ganglia or cerebellar harm, for example, hemorrhages and tumors can disable ability learning. Degenerative sicknesses that influence the basal ganglia and cerebellum, nonetheless, are the most widely recognized reasons for procedural memory issue [38]. In PD, degeneration of the substantia nigra of the midbrain happens, leaving the striatum in the basal ganglia drained of dopamine and along these lines broken. In Huntington illness (HD) [39-41], degeneration happens principally in the caudate core of the striatum and is most likely identified with irregular articulation of the protein chasing in. Numerous studies have contrasted patients with AD with those with HD or PD. The outcomes from these studies are clear. Since the pathology of AD influences cortical and limbic structures while saving basal ganglia and cerebellar structures, patients with $\mathrm{AD}$ indicate shortfalls of verbose memory yet procure procedural abilities at a typical rate. Right on time in the malady, patients with HD and PD exhibit close ordinary rambling memory execution, however, indicate impedances in their capacity to gain expertise learning. Essentially, patients with cerebellar degeneration additionally demonstrate deficiencies in procedural memory [41-43].

\section{CONCLUSION}

Customarily, memory has been seen as a basic idea. Truth be told, the utilization of different strategies has delivered joining and reciprocal lines of confirmation, proposing that memory are made out of partitioned and unmistakable frameworks. A solitary illness procedure (for example, Alzheimer's malady) may weaken more than one memory framework. Enhanced comprehension of the sorts of memory will 
help clinicians in the analysis and treatment of their patients' memory issue. This information will turn out to be progressively essential as more particular procedures rise for the treatment of memory brokenness. In spite of the fact that memory may show up as a unitary idea, in this article, we have surveyed proof that it is in actuality made out of independent and dissociable memory frameworks. We have concentrated principally on the roundabout memory framework, talked about how this framework can be influenced by ailments influencing the average worldly projections, the limbic framework or the frontal flaps, and how memory bends may come about. We then quickly talked about the other memory frameworks, which ailments influence them, and how these frameworks stand out from the long winded memory framework. Ultimately, we additionally said a portion of the subjective neuroscience investigate that has permitted us to.

\section{REFERENCES}

1. Newman MF, Kirschner JL, Phillips-Bute B, Gaver V, Grocott H, Jones RH, et al. Longitudinal assessment of neurocognitive function after coronary-artery bypass surgery. N Engl J Med 2001;1. 344(6):395-402.

2. Mesulam MM. Principles of Behavioral and Cognitive Neurology. $2^{\text {nd }}$ ed. New York: Oxford University Press; 2000.

3. Schacter DL, Tulving E. Memory Systems 1994. Cambridge, Mass: MIT Press; 1994.

4. Squire LR. Memory and the hippocampus: A synthesis from findings with rats, monkeys, and humans. Psychol Rev 1992;99(2):195-231.

5. Wagner AD, Schacter DL, Rotte M, Koutstaal W, Maril A, Dale AM, et al. Building memories: Remembering and forgetting of verbal experiences as predicted by brain activity. Science 1998;281(5380):1188-91.

6. Brewer JB, Zhao Z, Desmond JE, Glover GH, Gabrieli JD. Making memories: Brain activity that predicts how well visual experience will be remembered. Science 1998;281(5380):1185-7.

7. Papez JW. A proposed mechanism of emotion. Arch Neurol Psychiatry 1937;38(4):725-43.

8. Ribot T. In: Smith WH, editor. Diseases of Memory: An Essay in the Positive Psychology. The International Scientific Series. Vol. 41. New York: Appleton; 1882.

9. Simons JS, Spiers HJ. Prefrontal and medial temporal lobe interactions in long-term memory. Nat Rev Neurosci 2003;4(8):637-48.

10. Petrides M. The mid-ventrolateral prefrontal cortex and active mnemonic retrieval. Neurobiol Learn Mem 2002;78(3):528-38

11. Johnson MK, Kounios J, Nolde SF. Electrophysiological brain activity and memory source monitoring. Neuroreport 1997;8(5):1317-20.

12. Kopelman MD, Stanhope N, Kingsley D. Temporal and spatial context memory in patients with focal frontal, temporal lobe, and diencephalic lesions. Neuropsychologia 1997;35(12):1533-45.

13. Johnson MK, O'Connor M, Cantor J. Confabulation, memory deficits, and frontal dysfunction. Brain Cogn 1997;34(2):189-206.

14. Budson AE, Sullivan AL, Mayer E, Daffner KR, Black PM, Schacter DL. Suppression of false recognition in Alzheimer's disease and in patients with frontal lobe lesions. Brain 2002;125:2750-65.

15. Budson AE, Price BH. Memory: Clinical disorders. In: Encyclopedia of Life Sciences. Vol. 11. London: Nature Publishing Group; 2002. p. 529.

16. Solomon PR, Budson AE. Alzheimer's disease. Clin Symp 2003;54:1-40

17. Folstein MF, Folstein SE, McHugh PR. "Mini-mental state". A practical method for grading the cognitive state of patients for the clinician. J Psychiatr Res 1975;12(3):189-98.

18. Blessed G, Tomlinson BE, Roth M. The association between quantitative measures of dementia and of senile change in the cerebral grey matter of elderly subjects. Br J Psychiatry 1968;114(512):797-811.

19. Welsh KA, Butters N, Mohs RC, Beekly D, Edland S, Fillenbaum G, et al. The consortium to establish a registry for Alzheimer's disease (CERAD). Part V. A normative study of the neuropsychological battery. Neurology 1994;44(4):609-14.

20. Solomon PR, Hirschoff A, Kelly B, Relin M, Brush M, DeVeaux RD, et al. A 7 minute neurocognitive screening battery highly sensitive to
Alzheimer's disease. Arch Neurol 1998;55(3):349-55.

21. Winblad B, Engedal K, Soininen H, Verhey F, Waldemar G, Wimo A, et al. A 1-year, randomized, placebo-controlled study of donepezil in patients with mild to moderate AD. Neurology 2001;57(3):489-95.

22. Tariot PN, Farlow MR, Grossberg GT, Graham SM, McDonald S, Gergel I. Memantine treatment in patients with moderate to severe Alzheimer disease already receiving donepezil: A randomized controlled trial. JAMA 2004;291(3):317-24.

23. Moretti R, Torre P, Antonello RM, Cazzato G, Bava A. Use of galantamine to treat vascular dementia. Lancet 2002;360(9344):1512-3.

24. McKeith I, Del Ser T, Spano P, Emre M, Wesnes K, Anand R, et al. Efficacy of rivastigmine in dementia with Lewy bodies: A randomised, double-blind, placebo-controlled international study. Lancet 2000;356(9247):2031-6.

25. Cummings JL. Alzheimer's disease. N Engl J Med 2004;351(1):56-67.

26. Press DZ. Parkinson's disease dementia - A first step? N Engl J Med 2004;351(24):2547-9.

27. Schacter DL, Wagner AD, Buckner RL. Memory systems of 1999. In: Tulving E, Craik FI, editors. The Oxford Handbook of Memory. New York: Oxford University Press; 2000. p. 627-43.

28. Corkin S. Lasting consequences of bilateral medial temporal lobectomy: Clinical course and experimental findings in H.M. Semin Neurol 1984;4(2):249-59.

29. Vaidya CJ, Zhao M, Desmond JE, Gabrieli JD. Evidence for cortical encoding specificity in episodic memory: Memory-induced re-activation of picture processing areas. Neuropsychologia 2002;40(12):2136-43.

30. Damasio H, Grabowski TJ, Tranel D, Hichwa RD, Damasio AR. A neural basis for lexical retrieval. Nature 1996;380(6574):499-505.

31. Perani D, Cappa SF, Schnur T, Tettamanti M, Collina S, Rosa MM, et al. The neural correlates of verb and noun processing. A PET study. Brain 1999;122:2337-44.

32. Price JL, Morris JC. Tangles and plaques in nondemented aging and "preclinical" Alzheimer's disease. Ann Neurol 1999;45(3):358-68.

33. Lidström AM, Bogdanovic N, Hesse C, Volkman I, Davidsson P, Blennow K. Clusterin (apolipoprotein J) protein levels are increased in hippocampus and in frontal cortex in Alzheimer's disease. Exp Neurol 1998; 154(2):511-21.

34. Balota DA, Watson JM, Duchek JM, Ferraro FR. Cross-modal semantic and homograph priming in healthy young, healthy old, and in Alzheimer's disease individuals. J Int Neuropsychol Soc 1999;5(78):626-40.

35. Greene JD, Hodges JR. Identification of famous faces and famous names in early Alzheimer's disease. Relationship to anterograde episodic and general semantic memory. Brain 1996;119:111-28.

36. Hodges JR. Frontotemporal dementia (Pick's disease): Clinical features and assessment. Neurology 2001;56 11 Suppl 4:S6-10.

37. Heindel WC, Salmon DP, Shults CW, Walicke PA, Butters N. Neuropsychological evidence for multiple implicit memory systems: A comparison of Alzheimer's, Huntington's, and Parkinson's disease patients. J Neurosci 1989;9(2):582-7.

38. Daselaar SM, Rombouts SA, Veltman DJ, Raaijmakers JG, Jonker C. Similar network activated by young and old adults during the acquisition of a motor sequence. Neurobiol Aging 2003;24(7):1013-9.

39. Exner C, Koschack J, Irle E. The differential role of premotor frontal cortex and basal ganglia in motor sequence learning: Evidence from focal basal ganglia lesions. Learn Mem 2002;9(6):376-86.

40. Salmon DP, Lineweaver TT, Heindel WC. Nondeclarative memory in neurodegenerative disease. In: Troster AI, editor. Memin Neurodegenerative Disease: Biological, Cognitive, and Clinical Perspectives. Cambridge, England: Cambridge University Press; 1998. p. 210-25.

41. Sabe L, Jason L, Juejati M, Leiguarda R, Starkstein SE. Dissociation between declarative and procedural learning in dementia and depression. J Clin Exp Neuropsychol 1995;17(6):841-8.

42. Glisky EL, Schacter DL. Extending the limits of complex learning in organic amnesia: Computer training in a vocational domain. Neuropsychologia 1989;27(1):107-20.

43. Baddeley A. Recent developments in working memory. Curr Opin Neurobiol 1998;8(3):234-8. 